International Journal of Electrical Engineering and Technology (IJEET)

Volume 11, Issue 4, June 2020, pp. 159-168, Article ID: IJEET_11_04_018

Available online at https://iaeme.com/Home/issue/IJEET? Volume $=11 \&$ Issue $=4$

ISSN Print: 0976-6545 and ISSN Online: 0976-6553

DOI: https://doi.org/10.34218/IJEET.11.4.2020.018

(C) IAEME Publication

Scopus Indexed

\title{
INVERSE DEFINITE MINIMUM TIME RELAY COORDINATION IN RADIAL TRACTION SYSTEM
}

\author{
G. Suresh Babu \\ Professor, Department of Electrical and Electronics Engineering, \\ CBIT - Chaitanya Bharathi Institute of Technology, Hyderabad, Telangana, India \\ Sivasankar Venugopal \\ Associate Manager, KHMRTS - Keolis Hyderabad Mass Rapid \\ Transit System Limited, Hyderabad, Telangana, India \\ T. Murali Krishna \\ Associate Professor, Department of Electrical and Electronics Engineering, \\ CBIT - Chaitanya Bharathi Institute of Technology, Hyderabad, Telangana, India
}

\begin{abstract}
For stable and reliable operation of power system, the coordination of relays plays an important role. In order to achieve fast and selective protection, the relays are to be coordinated through appropriate relay settings with correct grading margins. Relay settings are to be done at upstream and downstream in such a way that proper coordination is achieved along various series networks. This paper presents different factors which play major part in selection of Inverse Definite Minimum Time (IDMT) over current protection on radial network. The selection of IDMT curves and procedure applied in relay settings such as Plug setting multiplier (PSM), Time settings multiplier (TSM), grading margins and different techniques used in relay coordination in a traction system are discussed.
\end{abstract}

Key words: Definite Minimum Time, Grading margins, Inverse definite minimum time, Plug Multiplier, Radial network, Relay coordination, Time multiplier, TimeCurrent curves, Traction system

Cite this Article: G. Suresh Babu, Sivasankar Venugopal and T. Murali Krishna, Inverse Definite Minimum Time Relay Coordination in Radial Traction System. International Journal of Electrical Engineering and Technology, 11(4), 2020, pp. 159-168.

https://iaeme.com/Home/issue/IJEET?Volume $=11 \&$ Issue $=4$ 


\section{INTRODUCTION}

During the fault conditions in the power system, the selected protection is the deciding factor in quantifying the significant impact of the harm caused by the short circuits. The damage and thermal stress caused by the fault condition is inversely proportional to the operating speed of the relays. Hence the faster the protection operates, the smaller the resulting hazards, damage and the thermal stress. On the other hand, collateral impact of voltage dip due to short circuit in the system will be shorter if the protection system operates faster thus preventing the healthy circuits of the network from shutdown due to under voltage. Faster and selective protection helps in achieving the load capability and reliability of the system[1]. To isolate the faulted part of network and to correctly identify the faulted section, good and reliable selectivity of the protection is essential. This makes it possible to direct the corrective action to the faulty part of the network and the supply to be restored as rapidly as possible. Hence proper care must be taken in the process of designing the fast protection, which can be achieved by a proper selection of the protection principle.

\section{POWER SYSTEM NETWORK}

Power system network consists of different components like Transformers, Circuit breakers, Current Transformers(CT), Potential Transformers(PT), cables etc. which are interconnected in a complex manner to provide power supply from source to the end consumer[2-3]. Power system has different type of networks based on the design and the utility requirement viz. Radial network, Parallel feeding network, Ring Main network and Interconnected Network.

The traction power system generally treated as radial network. In radial system, independent feeders radiate from a single substation/source and feed the distributors at one end only. In the system the feeders are serially looped from source to end consumer. The section nearest to the feeding point will be heavily loaded as circuit is serially configured. But it has limitations such as i)any fault on the feeder at upstream completely cuts off supply to the downstream consumers, ii) No alternate path of network to ensure redundancy and iii)The consumers at the distant end of the downstream network would be subjected to serious voltage fluctuations when the load on the distributor changes. Overcurrent protection is selected based on the network configuration i.e. Radial system or Ring main system. Non directional over current protection system is preferred as the network is serially looped. With time and current grading, the coordination of the protection relays can be achieved easily[4].

\section{RELAY COORDINATION}

A coordination study requires selection of all protective devices in the network right from the power supply to the downstream load side. In the coordination process comparative study to be made on the all the protective devices operating time in response to the different level of fault current in the network and the direction of fault current flow in case of directional overcurrent protection. The objective, of course, is to design a selectively coordinated electrical power system. The numerous data of the power system network are required to be collected and analysed for appropriate application of the relay grading margins for relay coordination. The data are required is i) Single-line diagram of the system under study, ii)System voltage levels, iii)Impedance and MVA data, iv)X/R ratio, v)Existing protection including relay device numbers and settings, CT ratios, and time-current characteristic curves, vi)Generator ratings and impedance data, vii)Transformer ratings and impedance data, viii)Motor ratings and impedance data, ix) Protective devices ratings including momentary and interrupting duty as applicable, $\mathrm{x}$ )Time-current characteristic curves for protective devices, $\mathrm{xi}$ )CT ratios, excitation curves, and winding resistance, xii) Thermal (I2t) curves for cables and rotating machines xiii) Conductor sizes and approximate lengths, xiv)Short-circuit 
and load current data, xv)Maximum and minimum momentary (first cycle) short-circuit currents at major buses, xvi)Maximum and minimum interrupting duty (5 cycles and above) short-circuit currents at major buses, xvii)Estimated maximum and minimum arcing and bolted ground-fault currents at major buses, xviii)Maximum load currents and xix)Motor starting currents and starting times[5-7].

The relay settings are first determined to give the shortest operating times at maximum fault levels and then checked to see if operation will also be satisfactory at the minimum fault current expected. The procedure recommended for conducting a coordination study is i) Select the fault current expected at the lowest voltage base or use the predominant voltage base. The alternatives are a common MVA base or a separate current scale for each system voltage, ii) Indicate short-circuit currents on the horizontal axis and relay operating time in $\mathrm{Y}$ axis of the log-log graph, iii)Indicate largest (or worst case) load ampacity on the horizontal axis, iv)Specify protection points which include magnetising inrush current of the machines and Thermal and magnetic limit of large power transformers, v) Indicate protective relay pick-up ranges, vi) Starting with the largest (or worst case) load at the lowest voltage level, plot the curve for this device on the extreme left side of the log-log graph, vii)Using a composite graph, trace the curves for all protective devices and ensure no overlapping of curves. In addition to the above procedures, the points to be considered in application of coordination study are a)It is always better to use relays which are connected in series in upstream and downstream of the network may have same operating characteristic and the relay located at the extreme downstream/farthest will have current settings equal to or less than the relays in the upstream.

Selectivity of the protection is mainly based on the selection of proper grading time and current. The grading time is the time difference between two consecutive stages of protection. The relay operating time during a heavy fault current condition should not be delayed and at the same time proper margin to be maintained to ensure selectivity. The grading margin principles are used in achieving the desired relay coordination in the power system network. Among the various possible methods used to achieve correct relay coordination are those using either time or overcurrent, or a combination of both. The common aim of all three methods is to give correct discrimination. Each type of grading must isolate only the faulty section of the power system network, leaving the rest of the system undisturbed and healthy. The constant values for the IEC IDMT curves are as follows as given in the table. 1

Table 1 The constant values for the IEC IDMT curves

\begin{tabular}{|l|c|c|c|}
\hline \multicolumn{1}{|c|}{ Curve Description } & $\boldsymbol{\beta}$ constant & $\boldsymbol{\alpha}$ constant & L constant \\
\hline IEC Standard Inverse Operate & 0.14 & 0.02 & 0 \\
\hline IEC Very Inverse Operate & 13.5 & 1 & 0 \\
\hline IEC Extremely Inverse Operate & 80 & 2 & 0 \\
\hline
\end{tabular}

IDMT curves can be selected as per the relay coordination requirement. The curves have different characteristics and give desired discrimination in time and current grading. So, the curves can be selected according to user and system requirement.

The time interval that must be allowed between the operation of two adjacent relays in order to achieve correct discrimination between them is called the grading margin. If a grading margin is not provided, or is insufficient, more than one relay will operate for a fault, leading to difficulties in determining the location of the fault and unnecessary loss of supply to some consumers. The main factors for grading margin are i)the fault current interrupting time of the circuit breaker, ii)Relay timing errors, iii)CT errors, iv) the overshoot time of the 
relay, v)final margin on completion of operation, vi)The safety margin considers the possible delay of the relay operation due to CT-saturation caused by the DC-component of the fault current and vii) The safety margin is also to be increased if auxiliary relays are used in the trip circuit of the circuit breaker.

Grading is initially carried out for the maximum fault level at the relaying point under consideration, but a check is also made that the required grading margin exists for all current levels between relay pick-up current and maximum fault level. The total interval required to cover the grading margin factors mentioned above depends on the operating speed of the circuit breakers and the relay performance. Generally, $0.5 \mathrm{~s}$ was a normal grading margin. With the invention of faster modern circuit breakers and a lower relay overshoot time, $0.4 \mathrm{~s}$ is reasonable, while under the best conditions even lower intervals may be practical. Though fixed grading margin adopted generally, but practically calculation of grading margin for each relay location is considered suitable. Fixed grading margin may be suitable at higher fault current levels which requires short relay operating times. At lower fault current levels, with longer operating times, the permitted error specified in IEC 60255 (7.5\% of operating time) may exceed the fixed grading margin, resulting in the possibility that the relay fails to grade correctly while remaining within specification. This requires consideration when considering the grading margin at low fault current levels. This more precise margin comprises a fixed time, covering circuit breaker fault interrupting time, relay overshoot time and a safety margin, plus a variable time that allows for relay and CT errors. Where relays of different technologies are used, the time appropriate to the technology of the downstream relay should be used. A suitable minimum grading time interval, $t^{\prime}$, may be calculated as given in equation.

$$
\mathrm{t}^{\prime}=\left[\left(2_{\mathrm{ER}}+2_{\mathrm{ECT}}\right) / 100\right] \mathrm{t}+\mathrm{t}_{\mathrm{CB}}+\mathrm{t}_{\mathrm{O}}+\mathrm{t}_{\mathrm{S}}
$$

where: $\mathrm{ER}=$ relay timing error $($ IEC 60255-4)

Ect $=$ allowance for $\mathrm{CT}$ ratio error $(\%)$

$\mathrm{t}=$ operating time of relay nearer fault $(\mathrm{s})$

$\mathrm{t}_{\mathrm{CB}}=\mathrm{CB}$ interrupting time $(\mathrm{s})$

$\mathrm{t}_{\mathrm{o}}=$ relay overshoot time $(\mathrm{s})$

$\mathrm{t}_{\mathrm{s}}=$ safety margin $(\mathrm{s})$

Relays of different types have different timing errors based on the design. Typical relay timing errors - standard IDMT relays are given in table 2.

Table 2 Typical relay timing errors

\begin{tabular}{|l|c|c|c|c|}
\hline \multirow{2}{*}{\multicolumn{1}{|c|}{ Parameters }} & \multicolumn{4}{c|}{ Relay technology } \\
\cline { 2 - 5 } & $\begin{array}{c}\text { Electro } \\
\text { mechanical }\end{array}$ & Static & Digital & Numerical \\
\hline Basic timing error \% & 7.5 & 5 & 5 & 5 \\
\hline Overshoot time (s) & 0.05 & 0.03 & 0.02 & 0.02 \\
\hline Safety margin (s) & 0.1 & 0.05 & 0.03 & 0.03 \\
\hline Overall grading margin & 0.4 & 0.35 & 0.3 & 0.3 \\
\hline
\end{tabular}

\section{RELAY CURRENT SETTING AND TIME SETTING CALCULATIONS}

An overcurrent relay has a minimum operating current, known as the current setting of the relay. The current setting must be selected that the relay is not expected to operate for the maximum load current in the circuit being protected but does operate for a current equal or greater to the minimum expected fault current. In general, the current setting will be selected to be above the maximum short time rated current of the circuit involved. Since all relays 
have hysteresis in their current settings, the setting must be sufficiently high to allow the relay to reset when the rated current of the circuit is being carried. The amount of hysteresis in the current setting is denoted by the pick-up/drop-off ratio of a relay - the value for a modern relay is typically 0.95 . Thus, a relay minimum current setting of at least 1.05 times the Full load current of the circuit is likely to be required.

\subsection{PMS Setting Criteria}

For IDMT protection the fault current is calculated based on the full load current at selective MVA of the system under study.

- Calculate the maximum through fault current of the transformer at secondary.

- Select the pick-up value of current at rated MVA.

- Select an IDMT curve based on the requirement.

- Calculate the full load current at desired MVA base.

- Calculation of plug setting PMS.

\subsection{Relay Trip Time Setting for IDMT Protection}

TMS -Time Multiplier Setting

- Select the pick-up value of current.

- Select the desirable tripping time (Td)

- PSM at Fault current.

- Calculate the relay operating time at calculated PSM with TMS at 1.

- Calculate the TMS required Desirable trip time.

\subsection{Time-Current Characteristic curves}

The correct co-ordination of overcurrent relays in a power system requires the calculation of the estimated relay settings in terms of both current and time. The resultant settings are then traditionally plotted in suitable $\log / \log$ format to show pictorially that a suitable grading margin exists between the relays at adjacent substations. Plotting may be done by hand, but nowadays is more commonly achieved using suitable software.

Time is plotted on the vertical axis and current is plotted on the horizontal axis of all timecurrent characteristic curves. Log-log type graph paper is used to cover a wide range of times and currents. Characteristic curves are arranged so that the area below and to the left of the curves indicate points of "no operation," and the area above and to the right of the curves indicate points of "operation." The procedure involved in applying characteristic curves to a coordination study is to select or set the various protective devices so that the characteristic curves of series devices from the load to the source are located on a composite time-current graph from left to right with no overlapping of curves. The result is a set of coordinated curves on one composite time current graph.

\section{CASE STUDY}

To give a practical insight in to the relay coordination a case study has been taken from the recent failure at Hyderabad metro rail receiving substation.

\subsection{Feeding Configuration at Receiving Sub Station}

Incoming power supply to receiving substation is $132 \mathrm{kV}$ from Main substation and further step down to two different voltage levels namely $33 \mathrm{kV}$ for auxiliary power supply and 27.5 
$\mathrm{kV}$ for traction power supply. In this case $27.5 \mathrm{kV}$ Traction power supply feeding configuration is considered.

- $132 \mathrm{kV}$ power supply received from Main Substation and through $132 \mathrm{kV}$ Incomer Circuit breaker (A), $132 \mathrm{kV}$ bus is charged.

- $132 \mathrm{kV}$ Traction transformer feeder circuit breaker (B) receives power supply from $132 \mathrm{kV}$ bus and feeds to $132 / 27.5 \mathrm{kV}$ traction transformer.

- $27.5 \mathrm{kV}$ at Traction transformer secondary is fed to $27.5 \mathrm{kV}$ Traction power supply Board through $27.5 \mathrm{kV}$ Incomer circuit breaker (C).

- $27.5 \mathrm{kV}$ Depot Feeder circuit breaker (D) feeds the Depot traction loads.

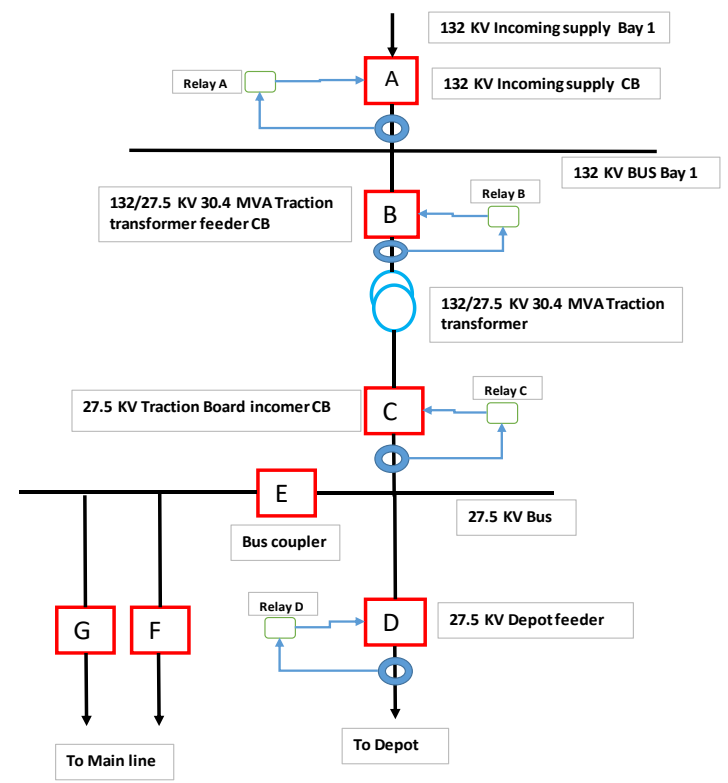

Figure 1 Feeding configuration of Traction power supply distribution

Kindly refer the fig. 1 for feeding configuration of Traction power supply distribution. Numerical protection relays have been given nomenclature as same as the circuit breakers protected by the relays.

\subsection{Problem Statement}

During a fault at depot traction system, kindly refer Fig no 4 for Circuit breaker nomenclature and location, the depot feeder circuit breaker (D) feeding the traction system tripped on DMT protection /Distance protection and along with that Traction transformer (132/27.5 kV 30 MVA) feeder circuit breaker (B) also tripped. Because of the tripping of Traction transformer feeder Circuit Breaker (B), complete traction power failed at $27.5 \mathrm{kV}$ bus and power disturbance happened in the main line feeding too.

The following steps are involved in analysis of failure

- Collection System details

- Collection Relay trip data - Fault current, operating time taken by the relay

- Information on Trip status of the Circuit breakers during the fault condition

- Collection of Present relay settings.

- Analysis of fault scenario

- Recommended relay settings 
- Calculation of relay operating time with new settings.

- Presentation of results

\subsection{System Details}

Table 3

\begin{tabular}{|l|l|l|}
\hline 1 & Primary voltage & $132000 \mathrm{~V}$ \\
\hline 2 & Secondary voltage & $27500 \mathrm{~V}$ \\
\hline 3 & Primary current & $230.3 \mathrm{~A}$ \\
\hline 4 & Primary max. fault current & $1909.09 \mathrm{~A}$ \\
\hline 5 & Secondary load current & $1099.2 \mathrm{~A}$ \\
\hline 6 & Secondary Max. fault current & $9163.63 \mathrm{~A}$ \\
\hline 7 & Fault MVA & 252 \\
\hline 8 & Transformer MVA & 30.24 \\
\hline 9 & MVA considered for existing calculation & 8 MVA \\
\hline
\end{tabular}

\subsection{Data Collected from the Failure for Analysis}

Fault current seen by the relay at Depot feeder: 4012.12 A

Fault current seen by the relay B at primary side of Transformer; 4012.12/Transformation ratio is $835.83 \mathrm{~A}$.

\subsection{Trip Status of the Circuit Breakers}

Circuit breaker D : Trip

Circuit breaker C : No Trip

Circuit Breaker B : Trip

Circuit Breaker A $\quad$ : No Trip

\subsection{Fault Analysis}

From the above Relay trip details, it has been analysed that

- Relay B at CB -B not to trip for the fault at the downstream side. Relay coordination to be checked.

- Relay Cat CB -C to trip in case of back up requirement but not tripped. Relay coordination to be checked with Relay D at downstream side and relay B at upstream side

\subsection{Data Collected from the Present Relay Settings}

The following anomalies has been found from the present relay settings of Relay B and Relay $\mathrm{D}$

- Relay D - DMT protection given for PMS 12.10 In (In = 200/1 A) So, for the fault current of 2420 amps the relay trips with time delay of 0.1 second.

- Relay D - Distance protection given with time delay of 0.1 second to cater the transient faults.

- Relay C - IDMT protection given for PMS 1.4 In (In = 1300/1 A) with TMS 0.07. So, relay will pick when fault current exceeds 1820A. 
- Relay B - For full load current calculation, transformer MVA to be considered as 30.4 MVA but 8 MVA calculated setting was still present as set earlier when transformer was partially loaded.

- Grading between relay B and C has been given as 0.08 seconds.

- From the above parameters of 8 MVA the PMS and TMS were calculated for Relay B

a. TMS -0.040

b. PMS -- 0.22

\subsection{Analysis of the Fault Scenario}

Based on the fault current intensity at the depot traction system, the calculations have been made to find the relay coordination between relays $\mathrm{B}, \mathrm{C} \& \mathrm{D}$. It is presented below in table no 4 for easy comparison.

Table 4

\begin{tabular}{|c|l|c|c|c|c|c|c|}
\hline $\begin{array}{c}\text { Relay } \\
\text { Designation }\end{array}$ & Location & $\begin{array}{c}\text { Protecti } \\
\text { on }\end{array}$ & CT ratio & TMS & PMS & $\begin{array}{c}\text { Fault } \\
\text { current(A) }\end{array}$ & $\begin{array}{c}\text { Calculated } \\
\text { trip time(s) }\end{array}$ \\
\hline B & $\begin{array}{l}\text { Traction } \\
\text { Transformer } \\
\text { Feeder CB }\end{array}$ & IDMT & $300 / 1$ & 0.04 & 0.22 & $\begin{array}{l}835.83(132 \\
\mathrm{kV} \text { side) }\end{array}$ & 0.109 \\
\hline C & $\begin{array}{l}27.5 \mathrm{kV} \\
\text { Board } \\
\text { Incomer CB }\end{array}$ & IDMT & $1300 / 1$ & 0.07 & 1.4 & $\begin{array}{l}4012.12(27.5 \\
\mathrm{kV} \text { side })\end{array}$ & 0.653 \\
\hline D & $\begin{array}{l}27.5 \mathrm{kV} \\
\text { Depot Feeder } \\
\text { CB }\end{array}$ & DMT & $200 / 1$ & 0.1 & 12.1 & $\begin{array}{l}4012.12(27.5 \\
\mathrm{kV} \text { side })\end{array}$ & 0.1 \\
\hline
\end{tabular}

From the table no 4 the following points can be clearly concluded that, Relay D -DMT protection trip time and Relay B - IDMT trip time is same for the fault current. That is the reason relay B sent the trip signal to Circuit breaker B when the same fault current is seen by the relays C \& D, Relay C trip time with Relay B and Relay D are not correctly coordinated. With relay $\mathrm{D}$ it has the positive margin of 0.553 seconds and with relay $\mathrm{B}$ it has negative margin of 0.544 seconds, The main reason for the inappropriate relay coordination in the above scenario has been identified as the relay settings has been calculated on the basis of 8 MVA load on the traction transformer. Time grading between the relays have been incorrect.

\section{Recommended Relay Settings for Appropriate Relay Coordination}

To overcome the discrepancies in relay coordination and resulting inappropriate operation of the relays, it has been decided to carry out the relay coordination by taking in to account of full load MVA of the transformer and necessary grading margins at every relay location considering its relative locations with other Relays in the circuit. Relay C and Relay B is found to be mis coordinated with each other and also with respect to relay $\mathrm{D}$ at extreme downstream. With newly selected full load MVA of the transformer as 30.24 MVA, the relay pickup current and Maximum through fault current have been calculated for the relay coordination. Also, operating time of the relays have been revised with reference to the upstream and downstream relays operating time by considering the time delay given in the downstream relay, safety margin and relay timing error.

For Relay D, the protection is selected as Definite Minimum time (DMT) and the relay trip time delay is given as 0.1 second, the Relay C and Relay B to be coordinated with Relay $\mathrm{D}$ appropriately by selecting the correct current and time grading. To enable the requirement relay setting calculation for relay $\mathrm{B}$ and Relay $\mathrm{C}$ is given below. 
With reference to the above calculation of relay operating time of relay B \& $\mathrm{C}$, it has been identified that with the new TMS \& PMS settings the relay operating time for the same faults current seen by the relay are different based on the time grading and current grading principles implemented.

At the fault current of $4012.12 \mathrm{~A}$ at the extreme downside of the $27.5 \mathrm{kV}$ system, the Relay D operates at time delay of 0.1 second. Concurrently the same fault current is seen by the relays $\mathrm{B} \& \mathrm{C}$ but operating time is different due the different TMS setting and PMS setting given as per the calculation above. Relay $\mathrm{C}$ operating time is calculated as per the new TMS and PMS is 0.302 seconds and Relay B operating time found as 0.458 seconds. It clearly indicates that with new relay setting, relay $\mathrm{B}, \mathrm{C} \& \mathrm{D}$ are coordinated appropriately with proper current and time gradings. Relay operating time at newly selected TMS and PMS for relay $\mathrm{B}, \mathrm{C} \& \mathrm{D}$ is given in the comparative table no 5 .

Table 5

\begin{tabular}{|c|l|c|c|c|c|c|c|}
\hline $\begin{array}{c}\text { Relay } \\
\text { Designatio } \\
\text { n }\end{array}$ & \multicolumn{1}{|c|}{ Location } & $\begin{array}{c}\text { Protectio } \\
\mathbf{n}\end{array}$ & $\begin{array}{c}\text { CT } \\
\text { ratio }\end{array}$ & TMS & PMS & $\begin{array}{c}\text { Fault } \\
\text { current(A) }\end{array}$ & $\begin{array}{c}\text { Calculate } \\
\text { d trip } \\
\text { time (s) }\end{array}$ \\
\hline B & $\begin{array}{l}\text { Traction } \\
\text { Transformer } \\
\text { Feeder CB }\end{array}$ & IDMT & $300 / 1$ & 0.082 & 0.84 & $\begin{array}{l}835.83(132 \\
\mathrm{kV} \text { side) }\end{array}$ & 0.458 \\
\hline C & $\begin{array}{l}27.5 \mathrm{kV} \text { Board } \\
\text { Incomer CB }\end{array}$ & IDMT & $1300 / 1$ & 0.052 & 0.93 & $\begin{array}{l}4012.12(27.5 \\
\mathrm{kV} \text { side) }\end{array}$ & 0.302 \\
\hline D & $\begin{array}{l}27.5 \mathrm{kV} \text { Depot } \\
\text { Feeder CB }\end{array}$ & DMT & $200 / 1$ & 0.1 & 12.1 & $\begin{array}{l}4012.12(27.5 \\
\mathrm{kV} \text { side })\end{array}$ & 0.1 \\
\hline
\end{tabular}

\section{CONCLUSION}

Coordination is a systematic application of current actuated devices in a power system, which in response to a fault or overload will remove only a minimum amount of equipment from service. The objective of relay co-ordination is to minimize the equipment damage. In line with the objective the foremost aim is to achieve proper selectivity and speed without sacrificing sensitivity and fast fault clearance time. For appropriate coordination of the relays in different locations of the power system PSM \& TSM are to be calculated with available data required for relay coordination. Current setting and time multiplier setting of all relays are considered as optimization parameters. Identification of fault and subsequent isolation of faulted section is achieved through appropriate relay coordination study. A coordination study provides data useful for selection of instrument transformers, protective relay characteristics and settings, fuse ratings, and other information pertinent to provision of optimum protection and selectivity in coordinating these devices. Through a case study on exclusive Traction system relay coordination has been studied and helped to arrive at a result of appropriate relay coordinated condition on upstream and downstream relays.

\section{REFERENCES}

[1] Distribution Automation Handbook Section 8.2 Relay Coordination - ABB

[2] Network protection and Automation guide - Schneider Electric

[3] MICOM P141 and P138 Numerical relay user manual Schneider Electric

[4] Coordinated power system protection Technical Manual - US army TM 5-811-14 
[5] Mehul kumar D Devdhariya, Vibhuti R. Adroja, Kajal M. Rafaliya, Prof. Manan M. Desai, (2017) "Power System Protection with Relay Co-Ordination" International Journal of Engineering Development and Research, Vol.5, Issue 2, pp.101-105

[6] Jayesh Patel, Prof. H.N. Prajapati, (2014) "Relay Coordination Using Different MethodsA Review" International Journal of Advance Engineering and Research Development (IJAERD), Vol.1, Issue 12, pp.180-184.

[7] Hima A. Patel, Vaibhav M. Sharma, Anuradha Deshpande (2015) "Relay Coordination using ETAP", International Journal of Scientific \& Engineering Research, Vol-6, Issue 5, pp1583-1588. 